\title{
AIR BUBBLE GENERATION THROUGH A SUBMERGED MICRO-HOLE
}

\author{
J.-C. SHYU, P.-P. DING, W.-F. CHENG and P.-H. CHEN \\ Department of Mechanical Engineering, National Taiwan University, Taiwan, Republic of China.
}

$\mathrm{T}$

he aim of the present study are visualization and prediction of passively generated air bubbles through a submerged micro-hole. A simple orifice model, which has been used in most previous studies for bubble formation through an orifice, is modified by considering the friction loss of air flow in a micro-hole with moderate length-to-diameter ratio (4.38 to 13.64). The required driving pressure difference for the generation and detachment of an air bubble can be obtained. In the measurement, liquid was constantly drained out of a test chamber to induce a gradual decrease in chamber air pressure. Air bubble was generated once a threshold pressure difference was reached. The generations of air bubble were observed at liquid drained rates of $0.006,0.01,0.02,0.035,0.05$, and $0.100 \mathrm{ml} \mathrm{s}^{-1}$ through test plates with hole diameters of $1200,580,220,130,92$, and $60 \mu \mathrm{m}$, respectively. The predicted volume of a detached bubble and the threshold driving pressure difference for bubble generation and detachment agree well with the measured results. The pressure difference variation in the test chamber can be well predicted by this proposed approach.

Keywords: micro-hole; moderate length-to-diameter ratio; driving pressure difference; detached bubble volume.

\section{INTRODUCTION}

In recent years, the market need for inkjet printers has dramatically increased due to its low price for color printing. For a typical thermal inkjet printhead, lower pressure in the ink cartridge than the atmospheric pressure is designed to avoid ink leakage from the ejection nozzle. However, the continuous ejection of ink during the printing process reduces the chamber air pressure in the cartridge. To ensure a continual ink ejection, a bubble generator in the ink cartridge ${ }^{1}$, as shown in Figure 1(a), is used to automatically generate bubbles through holes with an extended length open to the atmosphere when the pressure drops to a designed value. The generated bubble will float through the liquid and break in the air chamber to balance the pressure difference. If bubbles are not generated as required, the printing quality of the printhead will be affected. The required pressure difference between the atmosphere and the air chamber for bubble generation depends on the size and shape of hole open to the atmosphere. A hydraulic diameter of $10 \mu \mathrm{m}$ is used. The reason for studying bubble generation and detachment through micro-holes is to see the usefulness for the design of bubble generator of an inkjet printhead. Therefore, a designed experimental model has been employed to study the bubble generation mechanism, as shown in Figure 1(b).

For a submerged orifice, the formation and detachment of bubbles have been reported in numerous theoretical and experimental studies. There are two kinds of bubble forma- tion models according to the bubble growth shape. The first group is the spherical bubble formation model based on an assumption of spherical bubble growth, such as the models proposed by Davidson and Schüler ${ }^{2,3}$, and Kumar et al. ${ }^{4-6}$ However, the bubble detachment criterion of the spherical bubble formation model has not been justified ${ }^{7}$. The second group includes the non-spherical models such as those proposed by Marmur and Rubin ${ }^{8}$ as well as Pinczewski ${ }^{9}$. In the study of Pinczewski ${ }^{9}$, the effect of gas momentum was also included in the force balance on the bubble surface.

In most the prior experiments, bubbles are formed by passing gas flow into a gas chamber attached beneath the orifice. It is well known that the dimension of an attached gas chamber has a significant effect on the bubbles formed under this situation. A dimensionless parameter, $N_{c}$, was therefore defined by Hughes et al. ${ }^{10}$ to distinguish whether a bubble was formed under constant pressure, intermediate, or constant flow conditions. Park et al. ${ }^{11}$ elaborated the dimension effect of the attached chamber on the bubble volume. In addition, the detached bubble volume will also be affected by the gas flow rate.

For the bubble generator of an ink cartridge, the gas flowing through the micro-hole is neither at a constant flow rate nor under constant pressure because the pressure difference between the atmosphere and the chamber varies during the ink ejection. Moreover, the length-to-diameter ratio of a micro-hole is comparatively larger than an orifice. Each length-to-diameter ratio has a specific orifice constant. This study aims to investigate the pressure fluctuation in the 


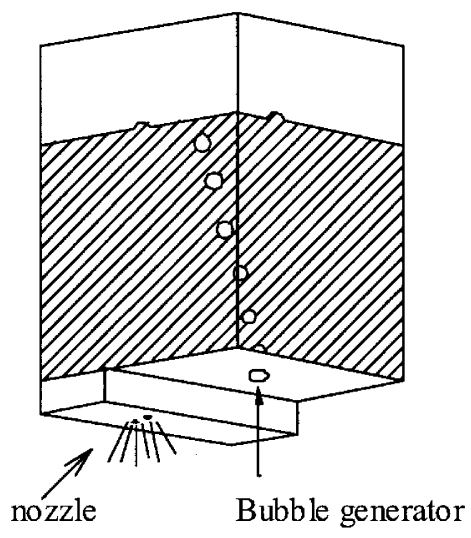

(a)

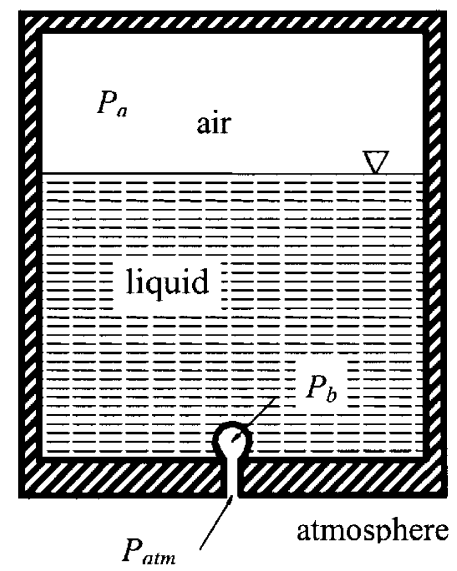

(b)

Figure 1. (a) A bubble generator of inkjet printhead; (b) schematic diagram for modelling bubble generation and detachment in a bubble generator.

chamber of ink cartridge for bubble generation through a submerged micro-hole without an attached gas chamber beneath the hole. The present modified model can numeri- cally estimate the pressure loss through the micro-hole. Therefore, the experiments that are conducted to evaluate the orifice constant of each hole have been made redundant by the present modified model. The effect of air pressure variation in the test chamber on the bubble formation process is investigated. This modified model considers the friction loss of laminar gas flow in predicting both the volume of a detached bubble and the threshold driving pressure difference for the bubble generation and detachment in the micro-hole.

\section{EXPERIMENTAL METHOD}

A schematic view of the experimental apparatus is shown in Figure 2. The present setup consists of four major systems, namely a test chamber, a PC-controlled transverse system, a pressure measuring and recording system, and an image processing system. The inner dimension of the test chamber was $2.8 \times 3.3 \times 3.8 \mathrm{~cm}^{3}$. Two sidewalls of the chamber were made of copper, and the other two were transparent acrylic. Two holes were drilled at the bottom plate of the chamber; one with diameter of $4.5 \mathrm{~mm}$ for liquid drainage of the test chamber and the other was a micro-hole for bubble generation, as shown in Figure 3. The bottom plate was replaceable with test pieces of various micro-hole diameters. The diameters of 1200,580 and $220 \mu \mathrm{m}$ were respectively drilled on a brass plate with an uncertainty of $5 \mu \mathrm{m}$; For diameters of $130,92,60 \mu \mathrm{m}$, the micro-hole was respectively drilled on a polycarbonate sheet by an excimer laser $(193 \mathrm{~nm})$ with an uncertainty controlled within $1 \mu \mathrm{m}$. No gas chamber was used; the bottom end of the hole was connected to the atmosphere during measurement.

A transverse system was used to drain liquid at a constant rate. The drainage hole was connected to a syringe fixed on a linear transverse table that was controlled by a stepping motor with rotation speed ranging from 0.06 to $3000 \mathrm{rpm}$. The capacity of the syringe was $36 \mathrm{ml}$, and the travelling distance of the transverse table was $5 \mathrm{~mm} \mathrm{rev}^{-1}$. Thus, the drained volume was about $1.97 \mathrm{~cm}^{3} \mathrm{rev}^{-1}$. During measurement, a differential pressure transmitter (FOXBORO IDP10-

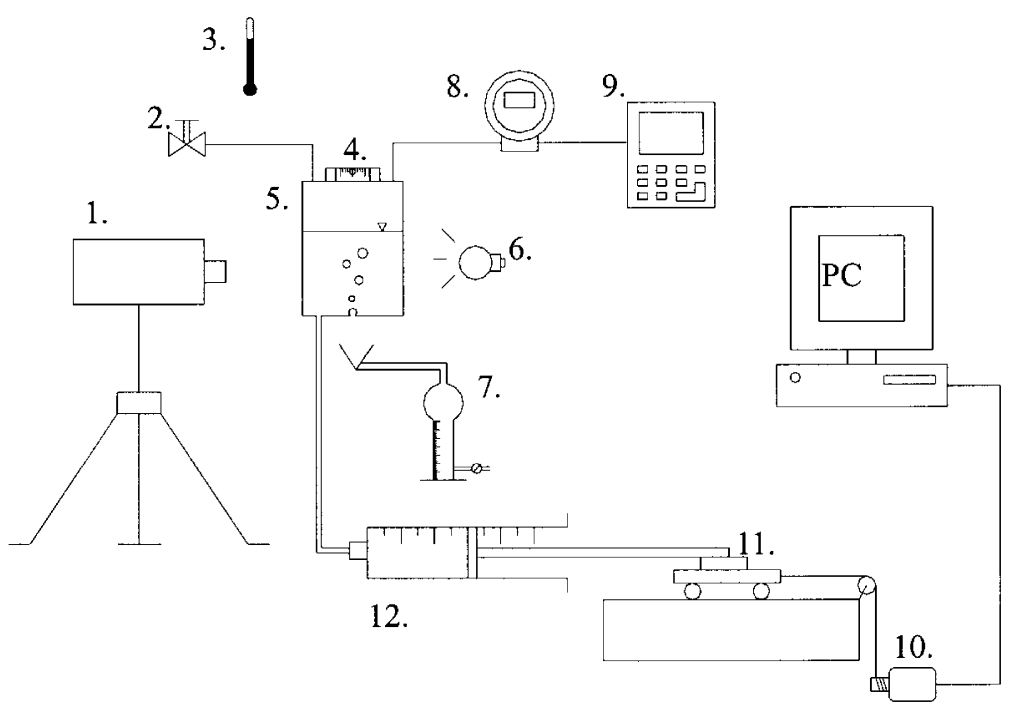

Figure 2. Schematic view of experimental apparatus: 1. High-speed video camera; 2 . Relief valve; 3 . Thermometer; 4 . Level gauge; 5 . Test chamber; 6. Halogen lamp; 7. Leakage receiver; 8. Differential pressure transmitter; 9. Handy recorder; 10. Stepping motor; 11. Platform of a linear transverse table; 12. Syringe. 


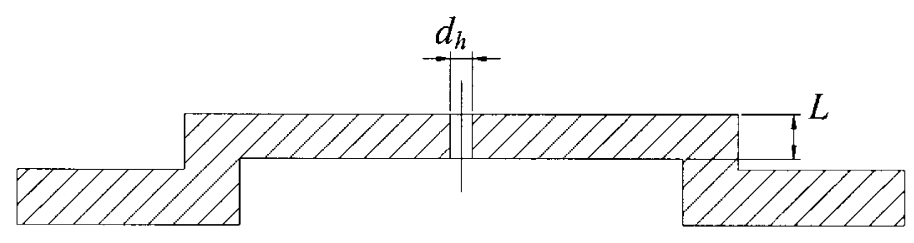

$$
\begin{aligned}
& L=3.0 \mathrm{~mm} \\
& d_{h}=1200,580,220 \mu \mathrm{m}
\end{aligned}
$$

(a)

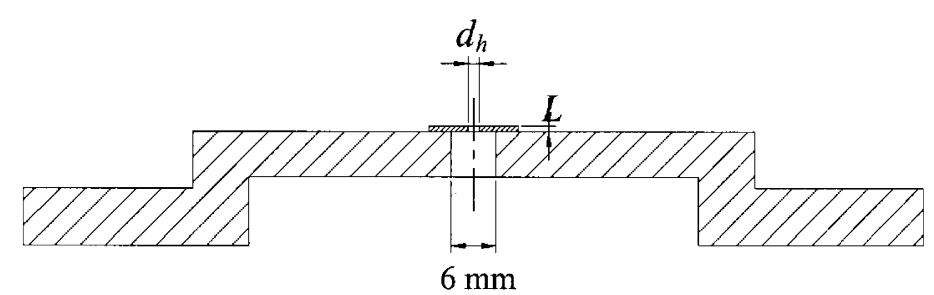

$$
\begin{aligned}
& L=570 \mu \mathrm{m} \\
& d_{h}=130,92,60 \mu \mathrm{m}
\end{aligned}
$$

(b)

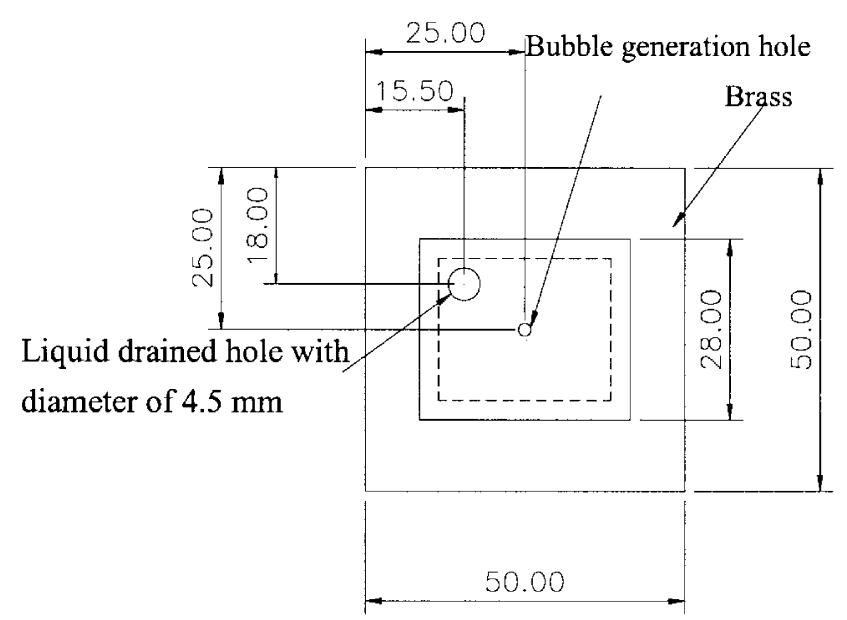

(c)

Figure 3. Schematic views of test plate: (a) a driller-drilled hole; (b) a laser-drilled hole; (c) top view of the bottom plate, unit: $\mathrm{mm}$.

A) with measuring range of $20 \mathrm{kPa}$, was used to measure the unsteady pressure fluctuation between the atmosphere and the air pressure in the test chamber, at an uncertainty of $20 \mathrm{~Pa}$. The unsteady pressure signal was transmitted to a recorder (YOKOGAWA, OR141-2/L2/PM) at a sampling rate of $16 \mathrm{~Hz}$.

An image processing system consists of a high-speed video camera (NAC color HSV-1000), a personal computer, and a high power halogen lamp. The high-speed video camera had a capturing rate of 1000 frames/sec and shutter rate of $1 / 2500$ second. The high power halogen lamp was used for brightness augmentation of the tiny bubbles' contour in taking high quality pictures. The recorded images were transmitted to a personal computer for the image analysis and the volume evaluation of detached bubble.

The experimental conditions used are listed in Table 1. The liquids used were water and $10 \%$ w.t. isopropanol aqueous solution. The surface tensions of water and isopropanol solution were measured by a drop weight method ${ }^{12}$, and the dynamic viscosities of water and isopropanol solution were measured using a programmable viscometer (Brookfield $\mathrm{DV} \mathrm{II}^{+}$), respectively. The uncertainties of surface tension and viscosity are $1 \mathrm{mN} \mathrm{m}^{-1}$ and $1 \%$ respectively. A leakage test was carried out before each measurement. Firstly, the micro-hole was sealed and the liquid in the test chamber was then suddenly drained until the air pressure in the test chamber decreased to a value around $9 \mathrm{kPa}$. The pressure signals were recorded for 20 minutes. If the increased air pressure of test chamber in this period was less than $5 \%$ of the initial pressure, which was $0.45 \mathrm{kPa}$, no leakage would be assumed.

The initial height of liquid level in the test chamber was kept at $3.5 \mathrm{~cm}$ before each measurement. The liquid was then drained out at a fixed rate during measurement. Six 
Table 1. Experimental conditions.

\begin{tabular}{|c|c|c|}
\hline Item & & Conditions \\
\hline Gas used & \multicolumn{2}{|l|}{ Air } \\
\hline $\begin{array}{l}\text { Dynamic viscosity } \\
\text { of gas, } \mu_{g}\end{array}$ & \multicolumn{2}{|l|}{$0.0181 \mathrm{mPas}$} \\
\hline Density of gas, $\rho_{g}$ & \multicolumn{2}{|l|}{$1.205 \mathrm{~kg} \mathrm{~m}^{-3}$} \\
\hline Liquid used & Water & $10 \%$ w.t. Isopropanol sol. \\
\hline $\begin{array}{l}\text { Dynamic viscosity } \\
\text { of water, } \mu_{l}\end{array}$ & $0.89 \mathrm{mPa} s$ & $1.51 \mathrm{mPas}$ \\
\hline Density of water, $\rho_{l}$ & $999 \mathrm{~kg} \mathrm{~m}^{-3}$ & $995.9 \mathrm{~kg} \mathrm{~m}^{-3}$ \\
\hline Surface tension of water, $\sigma$ & $71.5 \mathrm{mN} \mathrm{m}^{-1}$ & $39 \mathrm{mN} \mathrm{m}^{-1}$ \\
\hline Hole diameters, $d_{h}$ & \multicolumn{2}{|c|}{$1200,580,220,130,92,60 \mu \mathrm{m}$} \\
\hline Hole length, $L$ & \multicolumn{2}{|c|}{$\begin{array}{ll}3 \mathrm{~mm} & \text { for } d_{h}=1200,580 \text { and } 220 \mu \mathrm{m} \\
570 \mu \mathrm{m} & \text { for } d_{h}=130,92, \text { and } 60 \mu \mathrm{m}\end{array}$} \\
\hline $\begin{array}{l}\text { Liquid drained rate, } Q_{d} \\
\text { Environmental temperature }\end{array}$ & \multicolumn{2}{|c|}{$\begin{array}{l}0.006,0.01,0.02,0.035,0.05 \text {, and } 0.10 \mathrm{ml} / \mathrm{s} \\
24 \pm 1^{\circ} \mathrm{C}\end{array}$} \\
\hline
\end{tabular}

preset liquid drained rates $\left(Q_{d}\right), 0.006,0.01,0.02,0.035$, 0.05 , and $0.10 \mathrm{ml} \mathrm{s}^{-1}$, were respectively tested for each micro-hole, and a total amount of $10 \mathrm{ml}$ was drained for each test. When the air pressure in the test chamber decreased to a threshold value due to the continuous drainage, a bubble started to form at the air-liquid interface of the micro-hole. Once the bubble was detached, it may have floated through the liquid and broke at the liquid surface. Due to the supplement of air bubbles, the air pressure in the chamber continuously rose to a value, which would terminate the formation process. The air pressure in the test chamber varied with time and bubbles were continuously generated at the micro-hole due to continuous drainage. The time-dependent pressure difference were measured and recorded. The synchronous images were also captured. The images were transmitted to and analyzed on a computer to obtain integrate the volume of detached bubble.

\section{NUMERICAL APPROACH}

In spite of the deviation from the physical situation, the spherical bubble formation model is still used to model some problems, such as the work of Yang et al. ${ }^{13}$. Therefore, the present study revises the proposed model of Davidson ${ }^{2,3}$, due to some fundamental physical weaknesses in Kumar's Model $^{7}$. A bubble volume was calculated as a sphere in the present study, instead of a spherical segment above the orifice proposed by Lanauze and Harris ${ }^{14}$.

According to Davidson and Schüler ${ }^{2}$, an orifice equation is expressed as:

$$
Q(t)=\frac{d V}{d t}=K_{o}\left[P-\frac{2 \sigma}{(3 V / 4 \pi)^{1 / 3}}\right]^{1 / 2}
$$

where $Q(t)$ denotes the volumetric flow rate of gas into a bubble, $K_{o}$ is an orifice constant determined experimentally, $\sigma$ is the surface tension, $P$ is the gauge pressure at the inlet of the orifice, and $V$ is the volume of the spherical bubble, respectively.

For modelling the generation and detachment of an air bubble, the experimental system is simplified as shown in Figure 1(b). To obtain a relationship between the volumetric flow rate and the pressure loss across the micro-hole, the friction loss of air flow into the hole is considered in the present modified model that is absent in the orifice equation. The volumetric flow rate can be determined by:

$$
Q(t)=\frac{d V}{d t}=v \times \frac{\pi d_{h}^{2}}{4}
$$

where $v$ is the mean velocity in the hole, and $d_{h}$ is the diameter of hole. Assuming that the gas velocities at the inlet and exit of the hole are much smaller than the mean velocity in the hole, the mean velocity of gas flow in the hole can be determined from the head loss equation, expressed by:

$$
\frac{P_{a t m}}{\rho_{g} g}=\frac{P_{b}}{\rho_{g} g}+\frac{f L}{d_{h}} \frac{v^{2}}{2 g}+\Sigma K \frac{v^{2}}{2 g}
$$

where $f$ is the Darcy friction factor, $P_{a t m}$ and $P_{b}$ denote the atmospheric pressure and the bubble pressure, respectively. $\Sigma K$ is the summation of minor loss coefficients of gas flow caused by the sudden contraction effect at the entrance of micro-hole and the sudden expansion effect from micro-hole into bubble. In this study, the loss coefficient at the microhole entrance is assumed to be 0.5 . For the expansion from the pipe into bubble is assumed to be 1.0. The summation of minor loss, $\Sigma K$, is same as the value used by Tsuge et al. ${ }^{15}$ in estimating the pressure drop across a single orifice. Then, the mean velocity of gas flow in the micro-hole can be expressed as:

$$
v=\sqrt{\frac{2\left(P_{a t m}-P_{b}\right)}{\rho_{g}\left(\left(f L / d_{h}\right)+\Sigma K\right)}}
$$

Substituting equation (4) into equation (2) yields:

$$
\frac{d V}{d t}=\frac{\pi d_{h}^{2}}{4} \times \sqrt{\frac{2\left(P_{a t m}-P_{b}\right)}{\rho_{g}\left(\left(f L / d_{h}\right)+\Sigma K\right)}}=K_{h} \sqrt{\left(P_{a t m}-P_{b}\right)}
$$

where $K_{h}$ is the corresponding orifice constant for bubble generation at a submerged micro-hole used in this article. It is a coefficient corresponding to $K_{o}$ of equation (1) for a submerged orifice. Noted that the value of $K_{h}$ varies with friction factor which depends on the Reynolds number of gas flow in the hole. It is also worth noting that the pressure difference between the atmosphere and the bubble pressure can be obtained by measuring the pressure difference between the atmosphere and the air pressure above the liquid level in the test chamber, and the relationship is given by:

$$
P_{a t m}-P_{b}=P_{a t m}-P_{a}-\rho_{l} g H-\frac{2 \sigma}{r}
$$

where $H$ is the liquid height, $P_{a}$ is the air pressure above liquid level in the test chamber, and $r$ is radius of air bubble.

The length-to-diameter ratio used in this study ranges from 4.38 to 13.64. A laminar gas flow is assumed and the friction factor ${ }^{16}$ can be obtained by:

$$
f e_{d}=\frac{13.76}{\sqrt{L^{+}}}+\frac{64+1.25 /\left(L^{+}\right)-13.76 / \sqrt{L^{+}}}{1+0.000212 / L^{+2}}
$$


where $L^{+}$is the dimensionless hole length. The assumption of laminar flow in the hole is confirmed by the calculated results. The maximum $R e_{d}$ for water and isopropanol solution are respectively 1007.13 and 711.24 among all tested hole diameters.

In addition to radial expansion, $d V / d t$, another movement of the spherical bubble is the vertical translation due to buoyancy. The force balance on the bubble becomes:

$$
\frac{d}{d t}\left(M \frac{d s}{d t}\right)=\left(\rho_{l}-\rho_{g}\right) V g+\frac{4 \rho_{g} Q(t)^{2}}{\pi d_{h}^{2}}-6 \pi \mu_{l} \frac{d s}{d t} r
$$

where $M$ is virtual mass of the bubble, defined as $M=\left(\rho_{g}+(11 / 16) \rho_{l}\right) V, r$ is radius of air bubble, and $s$ is the distance from the bubble centre to the hole exit, respectively.

The detachment criterion for spherical bubble growth in the present study is $s=r$, which is the same as the model of Davidson and Schüler ${ }^{2}$. Thus, the pressure difference for bubble formation and detachment can be determined from equations (5) and (8), subject to initial conditions of $r=d_{h} / 2$ and $s=0, d s / d t=0$ at $t=0$. Instead of the fully developed flow assumption proposed by Tsuge et al. ${ }^{15}$ and Yang et $a l^{13}$, the present estimation of friction factor is based on entrance flow assumption. Hence, despite the bubble formation at an orifice with small length-to-diameter ratio, for formation through a long nozzle with large lengthto-diameter ratio can also be estimated by the present model. Moreover, the additional experiment needed to determine the orifice constant of each test piece in the conventional method can be excluded in this modified model.

\section{RESULTS AND DISCUSSIONS}

Figure 4 shows the variation of driving pressure difference $(d P)$ with time. In Figure 4 , the driving pressure difference $(d P)$ is defined as $d P=P_{a t m}-P_{a}-\rho_{l} g H=$ $P_{\text {atm }}-P_{i}$, where $P_{i}$ denotes pressure at the region right above the test plate. As previously noted, the initial air pressure inside the test chamber is the atmospheric pressure, and the liquid level is $3.5 \mathrm{~cm}$ high. The value of $\left(P_{a t m}-P_{a}\right)$ is obtained from the differential pressure transmitter, and the height of the liquid level can be determined from the amount of liquid drained. Thus, the value of $d P$ at $t=0$ is kept at $-3.5 \mathrm{~cm} \mathrm{H}_{2} \mathrm{O}$. As liquid is drained, the air pressure in the test chamber decreases. Consequently, the driving pressure difference increases from an initially negative value, $-3.5 \mathrm{~cm} \mathrm{H}_{2} \mathrm{O}$, to a positive value. When the pressure difference is large enough, the generation of air bubbles will be initiated. The chamber air pressure increases after air bubbles float through liquid and break at the liquid surface. As a result, the value of driving pressure difference drops from a local maximum value, $d P_{\max }$, when the air bubble breaks, to a local minimum value, $d P_{\text {min }}$, as shown in Figure 4. As liquid is still being drained, the driving pressure difference will rise again from $d P_{\text {min }}$. Thus, the variation of driving pressure difference is expected to show a zigzag pattern during measurement, and it is reasonable that a higher liquid drainage rate will result in a faster pressure drop. Starting from a value of $-3.5 \mathrm{~cm} \mathrm{H}_{2} \mathrm{O}$, the driving pressure difference undergoes a periodic variation and the value lies between $d P_{\text {max }}$ and $d P_{\text {min }}$ this is illustrated by two parallel lines in Figure 4 . Therefore, the bubble forms in a

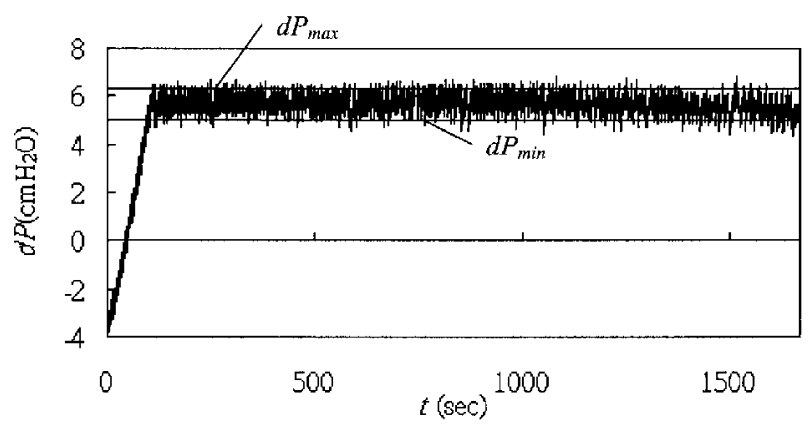

(a)

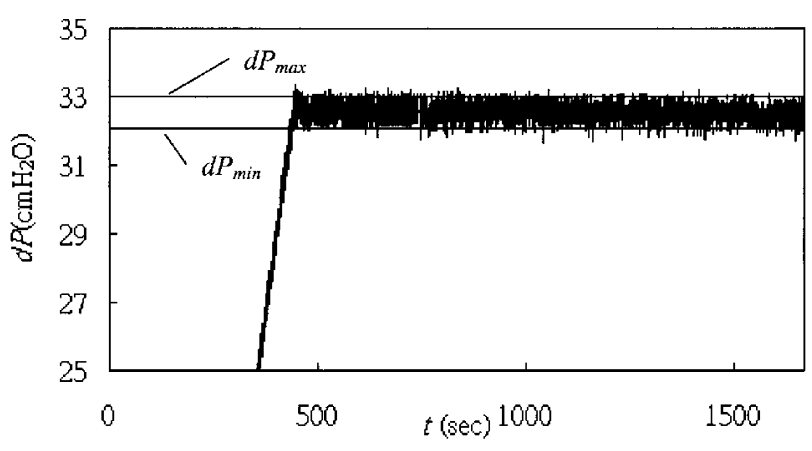

(b)

Figure 4. Variation of driving pressure difference with time for (a) $d_{h}=580 \mu \mathrm{m}$; (b) $d_{h}=92 \mu \mathrm{m}$; at $Q_{d}=0.006 \mathrm{ml} \mathrm{s}^{-1}$ of water.

passive way that depends on the pressure in the test chamber.

At liquid drained rates of $0.1 \mathrm{ml} \mathrm{s}^{-1}$ and $0.006 \mathrm{ml} \mathrm{s}^{-1}$, Figure 5 shows the respective variations of $d P_{\text {max }}$ and $d P_{\text {min }}$ with hole diameters. Equations for the solid lines in Figures 5(a) and 5(b) are expressed by:

$$
d P_{\text {max }}=\frac{4 \sigma}{d_{h}}, \quad d P_{\text {min }}=4 \sigma\left(\frac{1}{d_{h}}-\frac{1}{d_{b}}\right)
$$

where $d_{b}=\left((6 / \pi) V_{b}\right)^{1 / 3}$ denotes the measured detached bubble diameter and $V_{b}$ is the detached bubble volume. Excellent agreement is found between the measured results and the predicted values of $d P_{\max }$ and $d P_{\text {min }}$ with the tested hole diameters and liquid drained rates. Therefore, the threshold value of chamber air pressure is found to be $P_{a t m}-\rho_{l} g H-\left(4 \sigma / d_{h}\right)$ for the bubble formation at a chosen diameter. This threshold value is critical for printhead designer in simplifying the design of bubble generator.

In Figures 5(a) and 5(b), the variation of drained rate from $0.1 \mathrm{ml} \mathrm{s}^{-1}$ to $0.006 \mathrm{ml} \mathrm{s}^{-1}$ shows only a small effect on the values of $d P_{\text {max }}$ and $d P_{\text {min }}$. Therefore, it can be speculated that the variation of pressure difference in the test chamber is almost independent of liquid drainage rate, although the liquid drainage rate is time-dependent. This phenomenon is also verified by the predicted results showed in Figure 6 . The predicted values of $d P_{\max }$ increase slightly with the increase of liquid drainage rate. 


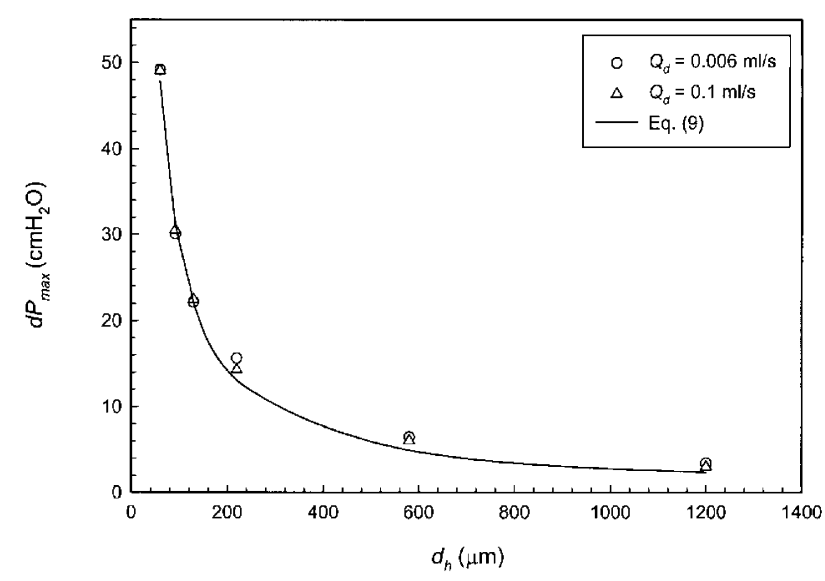

(a)

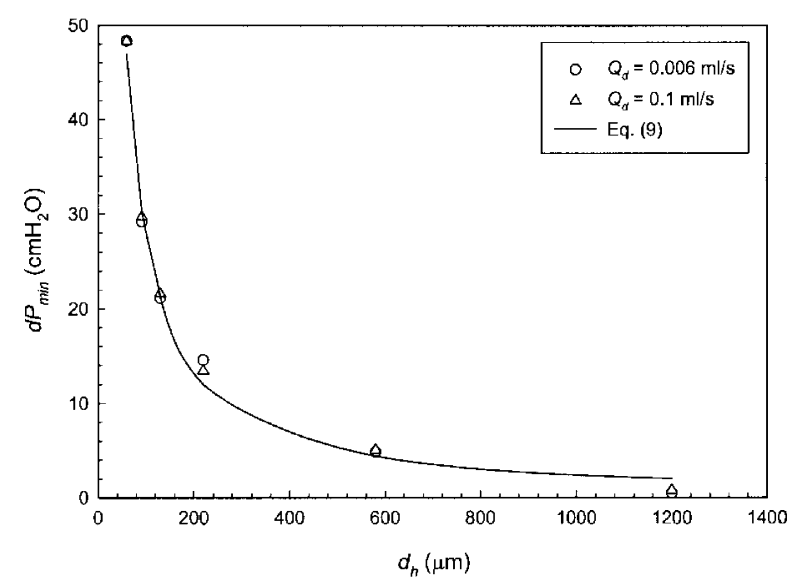

(b)

Figure 5. Variation of driving pressure difference with hole diameter, (a) $d P_{\text {max }}$; (b) $d P_{\text {min }}$; at two liquid drained rates of water.

As shown in Figure 7, the volume of a detached bubble, $V_{b}$, can be obtained from a typical visualized result for $d_{h}=60 \mu \mathrm{m}$ and $Q_{d}=0.006 \mathrm{ml} \mathrm{s}^{-1}$. Although the detached bubble is not in a perfect spherical shape but more likely an ellipsoid, the boundary of the detached bubble can still be easily found using a proper image processing procedure and can be used to determine the bubble volume by integration. For each measurement, the detached bubble volume was determined by taking an average value of ten different bubble volumes just detached from the hole with a maximum deviation of approximately $3 \%$. The maximum uncertainty in calculating detached bubble volume from the image is approximately $7 \%$, depending on the measured inaccuracy and pixel resolution.

From Figure 8, it can be seen that the detached bubble volume is almost the same under different drained rates. This is because only a different liquid drainage rate can change the rate of gas momentum transferred to a bubble. However, it is believed that the gas momentum effect on the bubble volume is very small in such an atmospheric pressure system. In addition, the bubble is generated as long as the threshold driving pressure difference is achieved. That is, a bubble will begin to form in the same pressure difference no matter what the liquid drainage rate for a specific microhole. The present results also show that the diameter of a detached bubble is about an order of magnitude larger than the diameter of the tested micro-hole. A comparison of the measured data and the predicted values of $V_{b}$ at various hole diameters at both the highest and the lowest liquid drained rates are also presented in Figure 8. In Figure 8 , the detached bubble volumes predicted by the modified model show satisfying agreement with the measured data at the hole's diameter smaller than $220 \mu \mathrm{m}$. However, for holes with a diameter larger than $220 \mu \mathrm{m}$, the deviation becomes obvious. This might be due to the volumes of bubbles generated at holes larger than $220 \mu \mathrm{m}$ which were comparatively large compared to the size of the test chamber. Hence, the growth of bubble could be restricted. The relatively large detached bubble in the test chamber could also induce an upward liquid flow cocurrently around the successively forming bubbles, and hence affected the growth size of the bubble ${ }^{17}$.

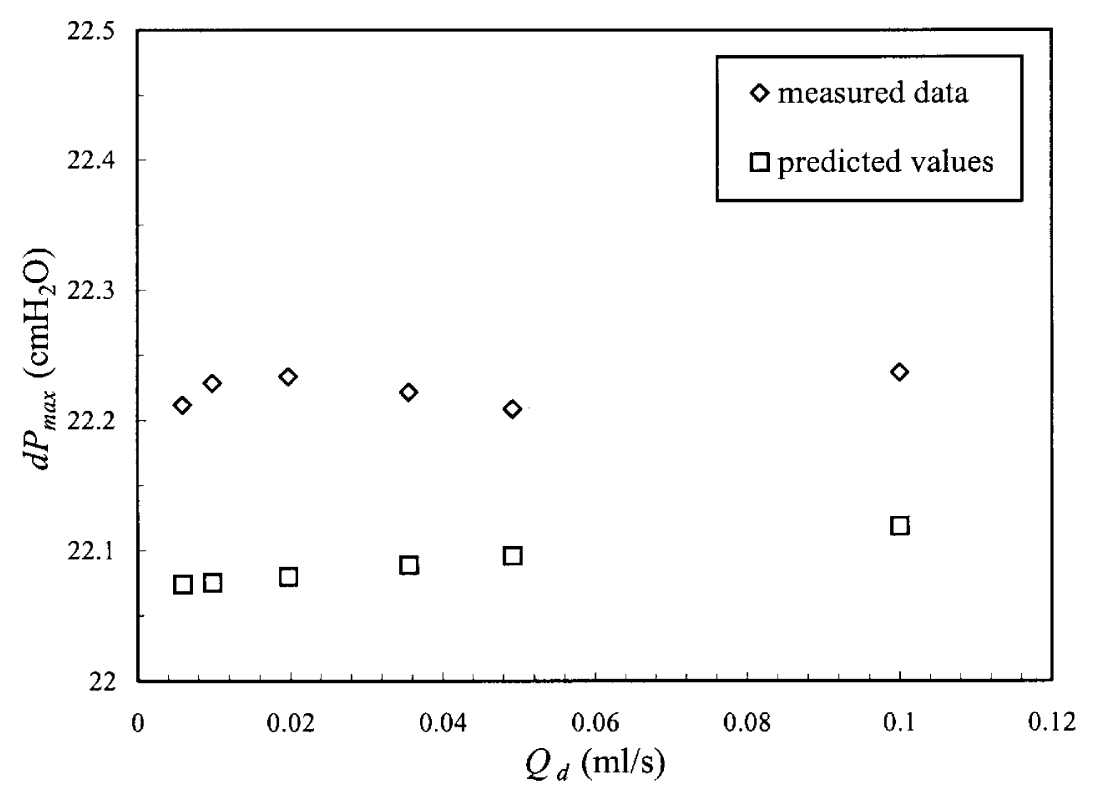

Figure 6. Comparison between predicted and measured $d P_{\max }$ for various liquid drained rates $\left(Q_{d}\right)$ of water at $d_{h}=130 \mu \mathrm{m}$. 
[or

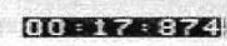

proportional scale: $5.06 \mathrm{~mm}$

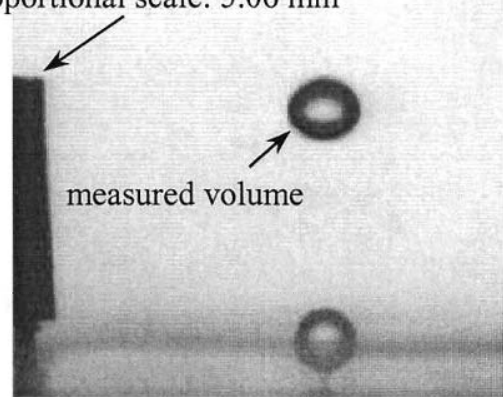

(a)

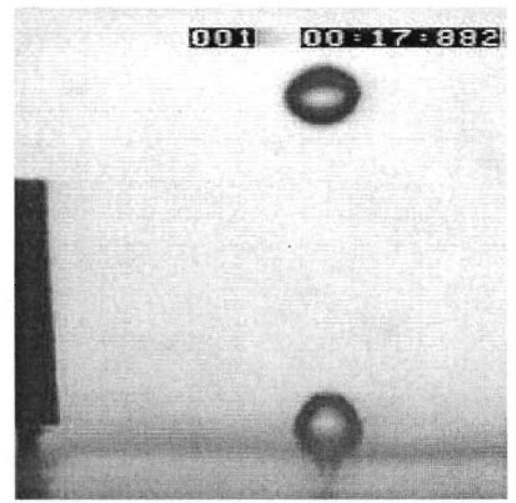

(c)

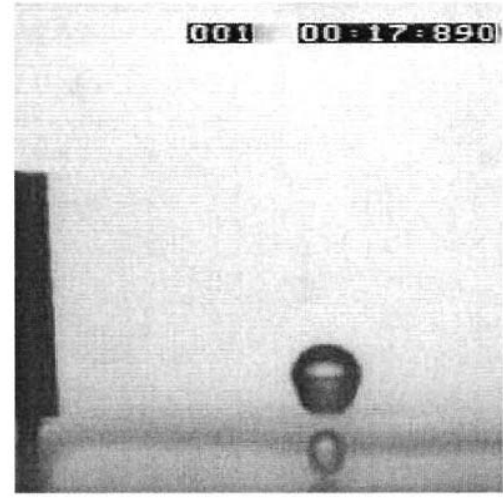

(e)

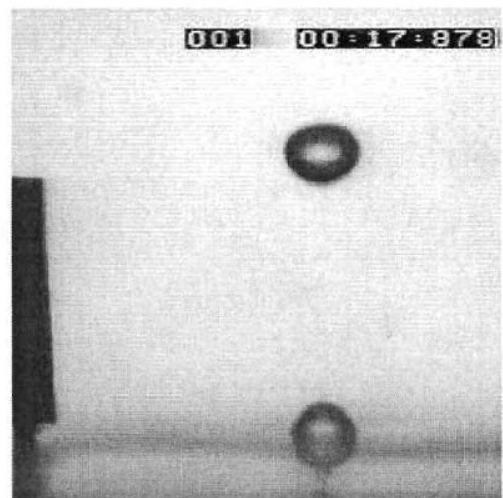

(b)

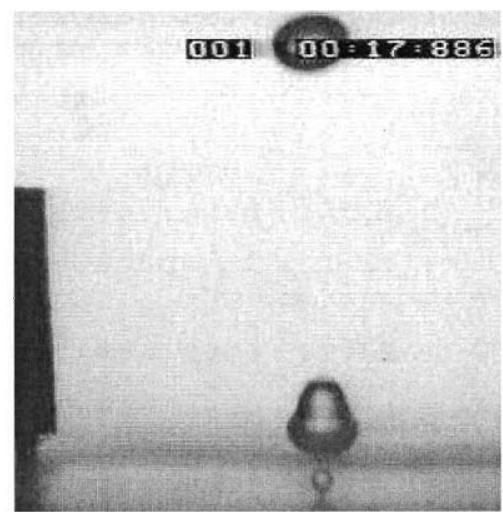

(d)

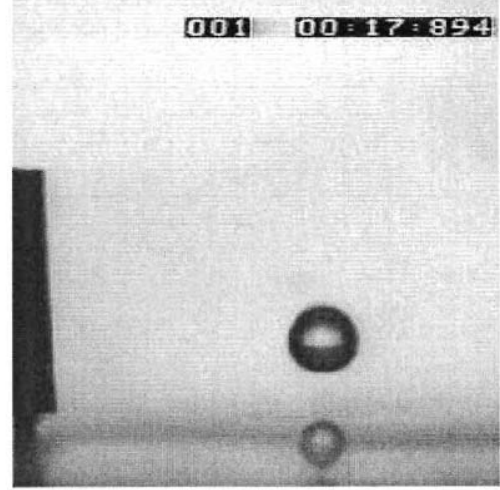

(f)

Figure 7. Visualized results of air bubble generation taken at a time interval of $4 \mathrm{~ms}$ for a test plate with $d_{h}=60 \mu \mathrm{m}$ and $Q_{d}=0.006 \mathrm{ml} \mathrm{s}{ }^{-1}$.

An equation is used to estimate the detached bubble volume generated at a small hole as follows:

$$
V_{b}=\frac{\pi d_{h} \sigma}{\left(\rho_{l}-\rho_{g}\right) g}
$$

Equation (10) shows that the surface tension is the predominant downward force for the vertical translation of a bubble. Other forces, such as viscous drag, inertial force and gas momentum effect can be reasonably neglected ${ }^{18,19}$. In Figure 8, the bubble volumes predicted by equation (10) are also included to compare with the experimentally measured data. The surface tension force, $\pi d_{h} \sigma$, is almost equal to the buoyancy force, $\left(\rho_{l}-\rho_{g}\right) V_{b} g$, that acts on the detached bubble volume generated at hole's diameter of $92 \mu \mathrm{m}$ as predicted by equations (5) and (8). That is:

$$
\frac{\pi d_{h} \sigma}{\left(\rho_{l}-\rho_{g}\right) V_{b} g} \geq 1
$$

Therefore, the bubbles generated at the hole's diameters smaller than $92 \mu \mathrm{m}$ seem to exist under a static force balance, which is the static bubbling regime stated by McCann and Prince ${ }^{20}$ for both liquids. In the static bubbling 


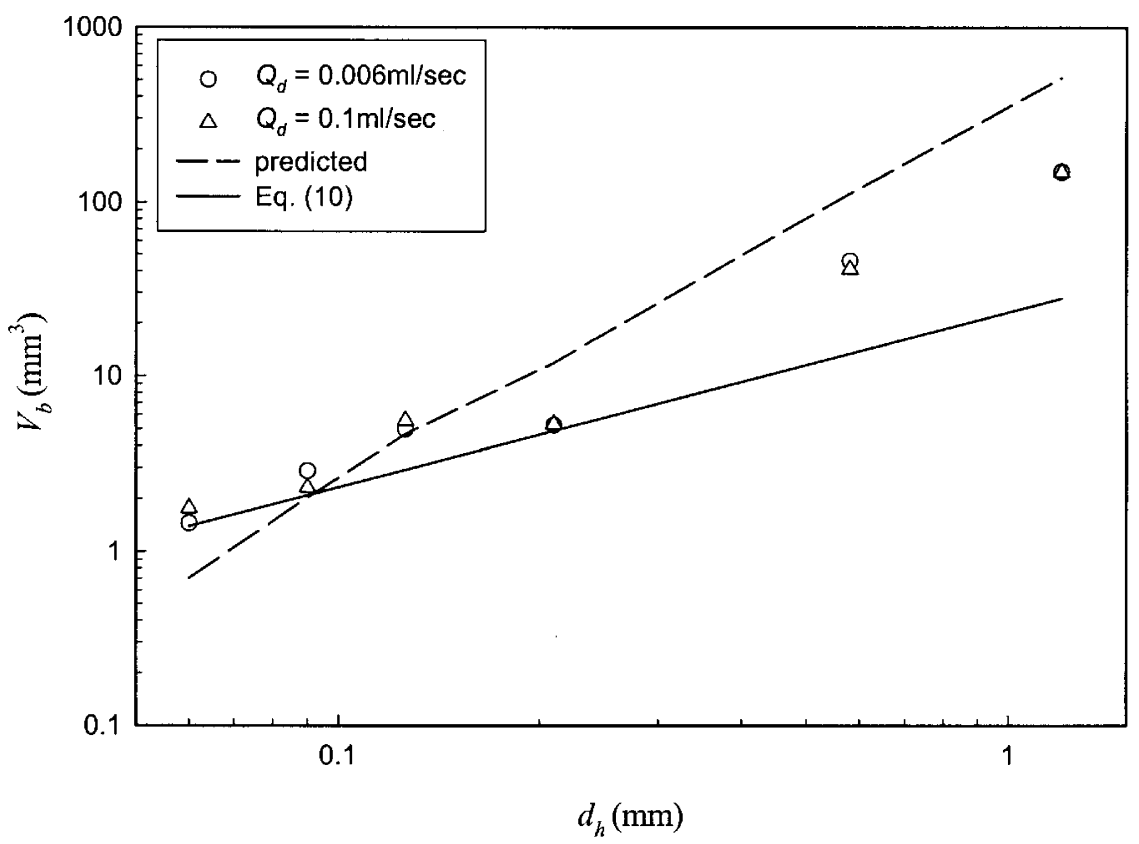

(a)

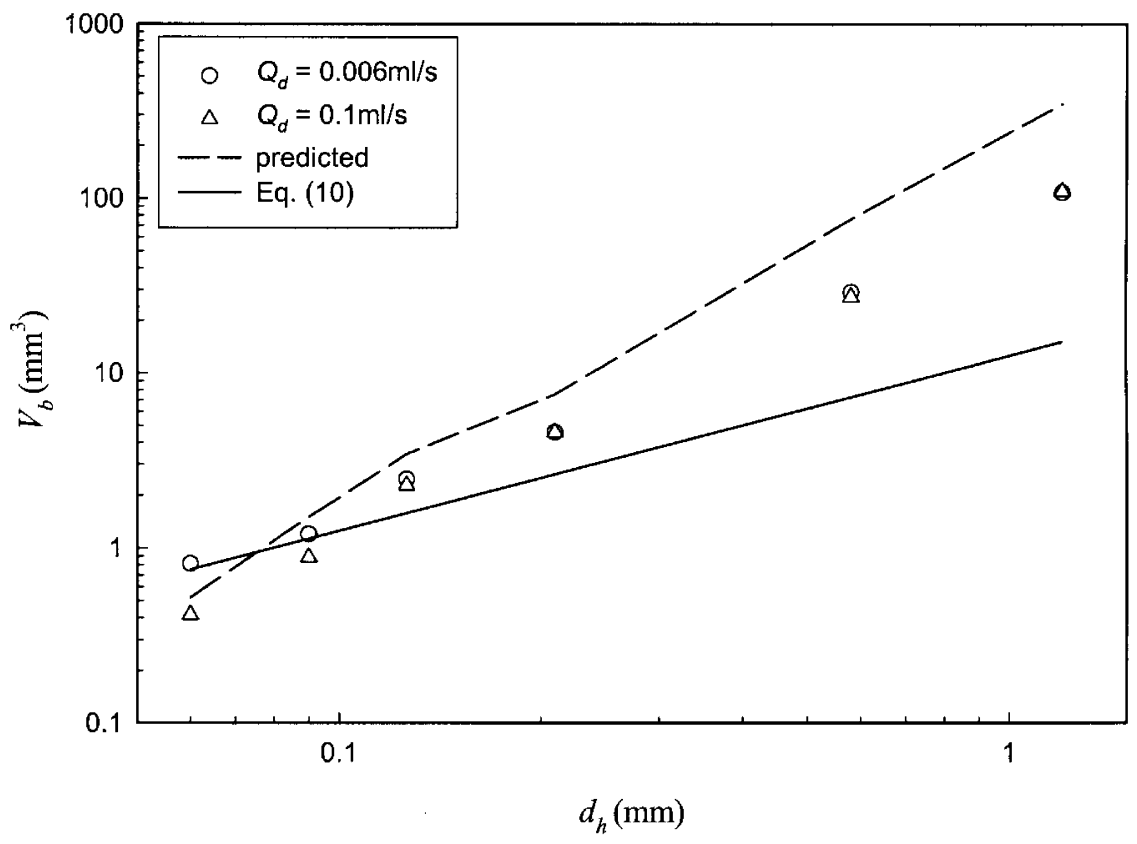

(b)

Figure 8. Comparison between predicted and measured values of $V_{b}$ at various hole diameters, (a) for water; (b) for isopropanol solution.

regime, the surface tension effect is significant. As a result, equation (11) should be included in the modified spherical model of the present study to estimate whether the buoyant force of the final bubble volume is larger than surface tension. If the buoyant force is larger than the surface tension, the value of detached bubble volume is determined. Otherwise, equation (10) will be used instead of solving equations (5) and (8) to increase the accuracy in estimating the detached bubble volume. In this experiment, the hole diameter that demarcates whether the bubbling regime is static or dynamic is approximately $92 \mu \mathrm{m}$ for both liquids. It is expected that the demarcated hole diameter will be shifted if different working fluid is used. However, by using the present proposed bubble volume evaluating procedure, it has been proved that the precision of the evaluated values can be effectively increased.

\section{CONCLUSION}

The experimental visualization and numerical prediction of the air bubble formation through a submerged micro-hole have been investigated in this study. The evolution of bubble generation was visualized and analyzed in the experiment. A bubble was generated passively without a gas chamber attached beneath the bubble formation hole. It was found that the pressure drop rate in the air chamber caused by 
liquid drainage has a minor effect on the required driving pressure difference, as well as the detached bubble volume. The threshold air pressure for the formation of air bubble at a hole submerged in liquid is approximately given by $\left(P_{a}\right)_{\text {thresh }}=P_{a t m}-\rho, g H-\left(4 \sigma / d_{h}\right)$, with one end of the hole exposed to the atmosphere. The air pressure in the test chamber undergoes a periodic variation that is caused by the stop-and-go process of bubbles generated at a constant liquid drainage rate. The driving pressure difference $(d P)$ lies between two limiting values, $d P_{\max }$ and $d P_{\text {min }}$.

The study of the pressure variation in the test chamber is significantly important in a system, such as a cartridge in an inkjet printer. Since the present results have proven that the pressure fluctuation is related to the detached bubble volume, it is crucial to accurately predict a detached bubble volume. For the numerical approach, a modified spherical model was used to predict both the driving pressure difference and the volume of generated bubble, which are not determinable from an orifice equation. The friction loss of air flow in the hole was considered in the calculations. Good agreements were found among the predicted and measured results for both $d P_{\max }$ and $d P_{\text {min }}$ (see equation (9)) under all test conditions. By simultaneously solving equations (5) and (8), the detached bubble volume can be precisely predicted for hole's diameter smaller than $220 \mu \mathrm{m}$. It is suggested that equation (11) should be essentially included as an auxiliary to increase the accuracy in estimating the detached bubble volume in the static bubbling regime, such as the results for hole's diameters smaller than $92 \mu \mathrm{m}$ in the present work. Consequently, the behaviour of bubble formation and detachment and the pressure difference response in the test chamber can be well predicted. Future efforts are to be made to improve the accuracy in predicting the bubble volume and to verify the application of this approach for other working fluids.

\section{NOMENCLATURE}

$d_{b}$
$d_{h}$
$d P$
$f$
$H$
$K$
$K_{h}$

detached bubble diameter, $\mu \mathrm{m}$

diameter of bubble formation hole, $\mu \mathrm{m}$

driving pressure difference, $\mathrm{cm} \mathrm{H}_{2} \mathrm{O}$

Darcy friction factor

liquid height in test chamber, $\mathrm{cm}$

orifice constant

corresponding orifice constant in this article,

$=\left(\pi d_{h}^{2} / 4\right) \times \sqrt{2 /\left(\rho_{g}\left(\left(f L / d_{h}\right)+\Sigma K\right)\right)}$

$L \quad$ hole length, $\mathrm{mm}$

$L^{+} \quad$ dimensionless hole length, $=L /\left(R e_{d} d_{h}\right)$

$M \quad$ virtual mass of bubble, $\mathrm{kg}$

$N_{c} \quad$ dimensionless capacitance number

$V \quad$ volume, $\mathrm{mm}^{3}$

$v \quad$ mean gas velocity in the hole, $\mathrm{m} \mathrm{s}^{-1}$

$P \quad$ pressure, $\mathrm{Pa}$

$R e_{d} \quad$ Reynolds number of gas flow in the hole

$Q \quad$ volumetric gas flow rate, $\mathrm{m}^{3} \mathrm{~s}^{-1}$

$Q_{d} \quad$ liquid drained rate, $\mathrm{ml} \mathrm{s}^{-1}$

radius of bubble, $m$

distance from the bubble center to the hole exit, $\mathrm{m}$

Greek symbols

$\sigma \quad$ surface tension, $\mathrm{mN} \mathrm{m}^{-1}$

$\begin{array}{ll}\rho & \text { density, } \mathrm{kg} / \mathrm{m}^{-3} \\ \mu & \text { viscosity, } \mathrm{mPas} \\ \Sigma K & \text { summation of minor loss coefficients } \\ \text { Subscripts } & \\ a & \text { air above liquid level in the test chamber } \\ \text { atm } & \text { atmosphere } \\ b & \text { detached bubble } \\ g & \text { gas } \\ l & \text { liquid } \\ \text { max } & \text { maximum } \\ \text { min } & \text { minimum }\end{array}$

\section{REFERENCES}

1. Cowger, B., 1992, IS and T's 8th International Congress on Advances in Non-Impact Printing Technologies (The Society of IS and T, Virginia, USA), pp 312-317.

2. Davidson, J. F. and Schüler, B. O. G., 1960, Bubble formation at an orifice in a viscous liquid, Trans IChemE, 38: 144-154.

3. Davidson, J. F. and Schüler, B. O. G., 1960, Bubble formation at an orifice in an inviscid liquid, Trans IChemE, 38: 335-342.

4. Ramakrishnan, S., Kumar, R. and Kuloor, N. R., 1969, Chem Eng Sci, 24: 731-747.

5. Satyanarayan, A., Kumar, R. and Kuloor, N. R., 1969, Chem Eng Sci, 24: 749-761.

6. Khurana, A. K. and Kumar, R., 1969, Chem Eng Sci, 24: 1711-1723.

7. Lanauze, R. D. and Harris, I. J., 1974, Chem Eng Sci, 29: 1663-1668.

8. Marmur, A. and Rubin, E., 1976, Chem Eng Sci, 31: 453-463.

9. Pinczewski, W. V., 1981, Chem Eng Sci, 36: 405-411.

10. Hughes, R. R., Handlos, A. E., Evans, H. D. and Maycock, R. L., 1955, AIChE J, 51: 557-563.

11. Park, Y., Tyler, A. L. and de Nevers, N., 1977, 32: 907-916.

12. Adamson, A. W., Physical Chemistry of Surfaces (Wiley, New York, USA), pp. 1-40

13. Yang, G. Q., Luo, X., Lau, R. and Fan, L. S., 2000, AIChE J, 46: $2162-$ 2174.

14. Lanauze, R. D. and Harris, I. J., 1972, Chem Eng Sci, 27: 2102-2105.

15. Tsuge, H., Tanaka, Y. and Hibino, S., 1981, Can J Chem Eng, 59: 569572 .

16. Shah, R. K., 1978, J Fluids Eng, 100: 177-179.

17. Terasaka, K., Tsuge, H. and Matsue, H., 1999, Can J Chem Eng, 77: 458 .

18. Blanchard, D. C. and Syzdek, L. D., 1977, 32: 1109-1112.

19. Lin, T. J., Tsuchiya, K. and Fan, L. S., 1998, AIChE J, 44: 545-560.

20. McCann, D. J. and Prince, R. G. H., 1971, Chem Eng Sci, 26: 15051512 .

\section{ACKNOWLEDGEMENTS}

The assistance of Professor K. J. Ma and his graduate student Mr. M. E. Zhu of the Department of Mechanical Engineering, Chung Cheng Institute of Technology, Taoyuan, Taiwan, in fabricating the micro-hole by using an excimer laser is greatly appreciated by the authors. The valuable suggestions from the reviewers are also greatly appreciated.

\section{ADDRESS}

Correspondence concerning this paper should be addressed to Professor P. H. Chen, Department of Mechanical Engineering, National Taiwan University, No 1 Roosevelt Rd, Section 4, Taipei, Taiwan 10617, Republic of China.

E-mail: phchen@ccmg.ntu.edu.tw
}

The manuscript was received 11 July 2001 via our international editor for Japan, Professor S. Koda, and was accepted for publication after revision 21 January 2002. 